\title{
Range shifts or extinction? Ancient DNA and distribution modelling reveal past and future responses to climate warming in cold-adapted birds
}

Running head: Avian palaeogenetics of climate change

Vendela K. Lagerholm ${ }^{1,2}$, Edson Sandoval-Castellanos ${ }^{1,2,3}$, Amélie Vaniscotte ${ }^{4}$, Olga R. Potapova ${ }^{5}$, Teresa Tomek ${ }^{6}$, Zbigniew M. Bochenski ${ }^{6}$, Paul Shepherd ${ }^{7}$, Nick Barton ${ }^{8}$, Marie-Claire Van Dyck ${ }^{9}$, Rebecca Miller $^{10}$, Jacob Höglund ${ }^{11}$, Nigel G. Yoccoz ${ }^{4}$, Love Dalén ${ }^{1 \not}$, John R. Stewart ${ }^{12 \ltimes \ltimes}$

1) Department of Bioinformatics and Genetics, Swedish Museum of Natural History, Stockholm, Sweden

2) Department of Zoology, Stockholm University, Stockholm, Sweden

3) Centro de Ciencias de la Complejidad, Universidad Nacional Autónoma de México, Ciudad de México, México

4) Department of Arctic and Marine Biology, UiT The Arctic University of Norway, Troms $\varnothing$, Norway

5) Mammoth Site of Hot Springs, SD, Inc. Hot Springs, USA

6) Institute of Systematics and Evolution of Animals, Polish Academy of Sciences, Kraków, Poland

7) British Geological Survey, Keyworth, Nottingham, UK

8) Institute of Archaeology, University of Oxford, Oxford, UK

9) Institute for the Analysis of Change in Contemporary and Historical Societies, Université catholique de Louvain, Louvain-la-Neuve, Belgium

10) Service of Prehistory, University of Liège, Liège, Belgium

11) Department of Ecology and Genetics, Evolutionary Biology Centre, Uppsala University, Uppsala, Sweden

12) School of Applied Sciences, Bournemouth University, Dorset House, Talbot Campus, Poole, Dorset, UK

${ }^{\ltimes}$ These authors contributed equally to the study

Corresponding authors: Vendela K. Lagerholm. +46 85195 5162. vendela.k.lagerholm@nrm.se Love Dalén. +46 85195 4281. love.dalen@nrm.se

Keywords: climate change, palaeogenetics, approximate Bayesian computation, species distribution modelling, phylogeography, colonisation, extinction, Pleistocene, Lagopus

Type of Paper: Primary Research Article 


\section{ABSTRACT}

1 Global warming is predicted to cause substantial habitat rearrangements, with the most severe effects 2 expected to occur in high-latitude biomes. However, one major uncertainty is whether species will be 3 able to shift their ranges to keep pace with climate-driven environmental changes. Many recent studies 4 on mammals have shown that past range contractions have been associated with local extinctions rather 
32 How organisms will respond to future global warming is a topic of considerable interest in conservation 33 management, and much effort is spent to explore different scenarios about the future state of species 34 distributions. Among the major uncertainties are if, and at what speed, species will be able to shift their 35 ranges in order to keep pace with changes in available habitat (e.g. Kerr et al. 2015). Thomas et al. (2004) predicted that $9-32 \%$ of all species will go extinct due to climate induced habitat loss by 2050 , assuming that they are able to colonise new areas as soon as these become climatically suitable. However, if this assumption is not met, the proportion of predicted species extinctions increases to 34-58 \% (Thomas et al. 2004). Successful range shifts could be highly dependent on the geographic connectivity between suitable habitat patches (Engler et al. 2009; Hodgson et al. 2012), and it has been suggested that only the populations already inhabiting refugial areas are the ones that survive range contractions (Bennett et al. 1991). These refugial populations may also obstruct the subsequent arrival of individuals from more remote areas through intra-specific competition (Hewitt 1996; Hewitt 1999). It has previously been difficult to evaluate whether range contractions actually do correspond to population contractions (i.e. habitat tracking), since modern phylogeographic analyses only give information about the surviving lineages. Lately though, ancient DNA techniques have made it possible to analyse temporal changes in genetic variation of cold-adapted taxa, from the last Ice Age up until today. Interestingly, these results have often shown that local extinctions and population turnovers, rather than survival by habitat tracking, were the dominant processes during past climate warming (e.g. Dalén et al. 2007; Lagerholm et al. 2014; Palkopoulou et al. 2016). This raises concerns from a conservation perspective, since such local extinctions following habitat loss could lead to ensuing losses of unique genetic variation. This is especially the case for the future viability of cold-adapted species, since the effects of on-going climate warming are expected to be most severe in northern biomes (Pithan \& 54 Mauritsen 2014; Serreze \& Barry 2011) and their ranges are already in a contracted state since the end of the last glaciation (Stewart et al. 2010). In order to make reliable predictions of future distributions and ensure effective conservation planning, it is therefore important to increase the knowledge about species' habitat tracking abilities (Kerr et al. 2015; Urban 2015).

58 Two cold-adapted bird species that co-occurred with the iconic Ice Age mammal fauna are the willow 59 ptarmigan (Lagopus lagopus) and rock ptarmigan (Lagopus muta). Since ptarmigan are important prey 
in the arctic ecosystem (e.g. Hansen et al. 2013; Nyström et al. 2005), and also have slightly different

61 environmental preferences, they together provide a good case-study to evaluate how cold-adapted 62 species are affected by climate-induced habitat shifts. Further, an important feature that distinguishes 63 them from previously investigated taxa is their flight capability which, although they have a sedentary 64 lifestyle, potentially could make dispersal to new areas less dependent on habitat connectivity (Pedersen 65 et al. 2004).

66 Today, the European ranges of ptarmigan are restricted to high altitude and/or high latitude regions, 67 with rock ptarmigan occupying the more alpine and sparsely vegetated areas (Fig. 1), but during the last 68 glacial period both species were widely distributed across the tundra-steppes of midlatitude Europe (e.g. 69 Tyrberg 1998). Morphological analyses of fossil remains of the two sister species have shown that both 70 were morphologically distinct and probably had greater body weights than their modern counterparts 71 (Bochenski 1985; Potapova 1986; Stewart 1999). However, it has not yet been established whether these populations represented specialised lineages that went extinct during end-Pleistocene climate warming, approximately 10 thousand years ago, or if the glacial populations in fact are the direct ancestors of modern European L. lagopus and L. muta (Höglund et al. 2013).

In this study, we have used an interdisciplinary approach consisting of ancient DNA analyses, Bayesian inference of coalescent simulations and back-casted species distribution modelling to analyse temporal changes in genetic variation and available habitat over the last 20 millennia. We evaluate two contrasting historic scenarios: 1) The glacial fossil remains from midlatitude Europe represent lineages that went extinct during the rapid warming of the early Holocene, and modern European ptarmigan populations have thus been established by postglacial immigrants from the Siberian population; or 2) The widespread glacial populations in Europe managed to track their shifting habitats into alpine and/or northern regions. In addition to investigating past responses, we also use species distribution modelling to forecast how global warming will affect ptarmigan distributions in the future, and discuss how knowledge of the past can influence conservation planning. 
MATERIALS AND METHODS

92 Genetic analyses

93 Samples and DNA Extraction

94 We collected Lagopus spp. bones from 73 Late Pleistocene individuals, ranging in age between $~ 11$ to 9527 thousand calendar years before present (cal kBP), from 10 paleontological sites across Europe (Table

96 S1). DNA was extracted from bone powder following Palkopoulou et al. (2013). In order to create a 97 reference dataset of the modern Holarctic genetic variation within both species, sequences from various 98 locations (Table S2 and S3) were downloaded from GenBank (see the Supporting Information). This 99 modern dataset was further complemented with modern samples from 34 willow and 13 rock ptarmigan 100 samples (Table S2 and S3), from which we extracted DNA following either the Palkopoulou et al. 101 (2013) protocol or the Qiagen DNeasy tissue kit according to Segelbacher et al. (2002).

102

103 DNA Amplification and Sequencing

104 A total of $240 \mathrm{bp}$ of the mitochondrial control region was amplified in three partially overlapping 105 fragments, using genus-specific primers developed for the study (Table S4). Some of the modern 106 samples were analysed at Uppsala University, Sweden, and polymerase chain reactions (PCRs) were 107 then made using the primers and protocol developed by Baba et al. (2001). Additional details regarding 108 DNA extraction, PCR amplification and sequencing are presented in the Supporting Information.

109 The pre-PCR work on the Late Pleistocene fossil remains were made in the ancient DNA laboratory at 110 the Swedish Museum of Natural History, which is physically isolated from the facilities for modern 111 material and post-PCR. All working surfaces and equipment were regularly sterilised with UV light, 112 bleach or hydrochloric acid, and all extraction and amplification reactions were made with blank 113 controls in order to monitor possible contamination. Further, at least two independent amplifications 114 were done in order to allow identification of erroneous bases caused by misincorporation during the 115 PCR process.

116 The obtained sequences were aligned and edited using the software SeqMan in the package Lasergene 117 v8.1.5 (DNASTAR) or the Muscle alignment algorithm in the package CodonCode Aligner 2.0.6 118 (CodonCode, USA). BioEdit v1.7.3 (Hall 1999) was then used to align our data with the downloaded 119 sequences from GenBank and build complete Holarctic datasets for willow and rock ptarmigan, 
respectively. These datasets were subdivided into the following geographic regions: Europe, consisting

121 of Western Europe (west of the White Sea) and Western Russia (between the White Sea and the Urals);

122 Siberia (Russia east of the Urals) together with North America; and Iceland, Svalbard and Greenland.

123 The wide geographic areas of the two latter groups were due to a corresponding labelling of many of the

124 downloaded GenBank sequences.

\section{Phylogenetic and Demographic analyses}

127 For each species, a temporal statistical parsimony network was created with the R-script TempNet v1.4 128 (Prost \& Anderson 2011) in order to display the haplotypes found in Late Pleistocene Europe, as well as 129 in modern populations world-wide. To further investigate the amount of population genetic structure in 130 the two species and evaluate the similarity between ancient European and modern Eurasian samples, we 131 used Arlequin v3.5.1.2 (Excoffier \& Lischer 2010) to compute analyses of molecular variance 132 (AMOVA). Based on distance matrices of pairwise differences and 10,000 permutations, we analysed 133 the following geographic and temporal hierarchical groupings: [modern and ancient Europe vs. modern 134 Siberia]; [modern Europe and Siberia vs. ancient Europe]; [modern Europe vs. modern Siberia and 135 ancient Europe].

136 Bayesian Skyline plots were constructed in BEAST v1.8.0 (Drummond et al. 2005; Drummond et al. 137 2012) to analyse population size changes over time in Western Europe (i.e. only Europe west of the 138 White Sea) for both species. We used the HKY+G nucleotide substitution model, as suggested by the 139 hLRT criterion in MrModeltest v2.3 (Nylander 2004), five groups, and a strict molecular clock with 140 mutation rates estimated from the data. Each analysis was run for 70 million generations, with 141 parameters logged every 1,000 generation, and the results were checked in TRACER v1.5 (Rambaut \& 142 Drummond 2007) to ensure convergence and effective sampling of all parameters.

\section{Approximate Bayesian Computation}

145 A model choice analysis by approximate Bayesian computation (ABC) coupled with coalescent 146 simulations was carried out for both species, in order to evaluate our two proposed hypotheses regarding 147 the most likely ancestral population to modern European birds. The simulated system was the same for 148 both species, and was based on the Eurasian dataset (see Table S2 and S3) with three statistical groups. 149 Modern Europe was set to coalesce with one of the two alternative ancestral populations between 12 and 
$30 \mathrm{cal} \mathrm{kBP}$, which in turn subsequently coalesced with the third remaining population between 30 and 120 cal kBP (Fig. 2).

After determining the most likely historic scenario for the origin of the modern European populations, we carried out another model choice analysis by $\mathrm{ABC}$ in order to investigate in more detail the demographic history of Western European (Europe west of the White Sea: Table S2 and S3) ptarmigan during the rapid climate warming at the Pleistocene-Holocene transition. Four different demographic scenarios were evaluated: a constant population size through time, a population increase or decrease, and a bottleneck (Fig. S1). From the chosen scenario we then estimated the parameters of interest, most notably effective population sizes at different time periods.

159 We performed the approximate Bayesian computation, including coalescent simulations and model choice analysis (scenario comparison), in the program BaySICS (Sandoval-Castellanos et al. 2014). The scenario comparison was made using Bayes factors, obtained for every pair of scenarios, using three different methods: a direct approach, an adjusted method (in which model likelihoods were weighted by an Epanechnikov kernel), and a logistic regression (Fagundes et al. 2007).

The analyses also included 50 replicates with increasing acceptance thresholds to assess the consistency. Pilot simulations and analyses were carried out in order to choose a proper set of summary statistics and to define optimal prior distributions (see Table S5). One million simulations were run in the pilot and the final simulations, respectively, and 5,000 of the accepted simulations were retained for further analysis. For both species, effective population sizes were first simulated from exponential priors (with $\lambda=250,000$ ) in order to sample homogeneously over a logarithmic scale to track a wide range of values, before employing uniform priors in the final simulations. The mutation rate had a uniform prior of 2.5 to $25 \%$ substitutions per million years $\left(\mathrm{Myr}^{-1}\right)$, covering the previously published rate for the two species of $6.5 \% \mathrm{Myr}^{-1}$ (Drovetski 2003) as well as the possibility of elevated rates in ancient DNA data sets (e.g. Ho et al. 2011). Additionally, in order to study the robustness of the results to parameter uncertainties, we performed replicates of the entire analysis considering very large mutation rates (up to $90 \% \mathrm{Myr}^{-1}$ ) as well as a genetic differentiation within modern Europe that could have begun at the onset of the Holocene climate warming. Finally, we cross-validated our results by analysing pseudo-observed 178 
181 Distribution and climatic data

182 The modern Eurasian ranges of willow and rock ptarmigan (Fig. 1) were compiled from the IUCN 183 database (BirdLife BirdLife_International 2012a; BirdLife BirdLife_International 2012b), with a 184 subsequent correction of the distribution in Russia according to Potapov and Potapov (2011). 185 Paleontological sites with Lagopus spp. remains were georeferenced from Tyrberg $(1998 ; 2008)$ and 186 classified in 1,000 year intervals, to be used as past presence data (Fig. 1).

187 The climatic variables used in the models were mean temperature and the sum of precipitation, 188 estimated for the summer (June, July, August and September) and winter (December, January, February 189 and March) as well as for the whole year (Fig. S2). These were selected due to their well-known ability 190 to explain plant species distributions, i.e. the main limiting resources for ptarmigan (Espíndola et al. 191 2012; Maiorano et al. 2013). Past climate data sets were created from a global ocean-atmosphere 192 climate model from the Hadley Centre (HadCM3) with a temporal resolution of 1,000 years, ranging 193 from the present and back to $20 \mathrm{cal} \mathrm{kBP}$, and corrected for anomalies such as in Maiorano et al. (2013). 194 We added a mask on the environmental variable corresponding to the Late Pleistocene ice sheets, with glacial data downloaded from NOAA's National Climatic Data Center (http://www.ncdc.noaa.gov/), as well as digitized from Darnault et al. (2012). Data on current climate (averaged from 1950 to 2000) and future climate projections (averaged from 2070 to 2100) were obtained from the Climatic Research Unit (Mitchell et al. 2004). For future climatic projections, we used data from the HadCM3 climate model in order to be consistent with past data. Two different IPCC (Intergovernmental Panel on Climate Change) future climatic scenarios were considered: the B1 scenario and the A2 scenario (IPCC 2001). Past, present and future environmental data were mapped over the European and Eurasian extent on a $0.5 \times 0.5^{\prime}$ resolution grid.

\section{Models}

The models were calibrated on current species presence/absence data and climatic conditions, using the R package BIOMOD (R Core Team 2014; Thuiller et al. 2009). Training data (species presence/absence and environmental covariates) were sampled randomly within species' modern distribution ranges. In a preliminary analysis we compared the predictive performances of different sampling strategies that differed regarding $i$ ) the size of the sample and $i$ ) the spatial extent of the sample (European versus 
210 Eurasian extent). Since the current climatic conditions in Siberia are considered to resemble those in 211 Europe during the Last Glacial Maximum, training the models on the whole Eurasian continent 212 (including Siberia) might increase the predictive power of ptarmigan occupancy for European 213 distributions during the Late Pleistocene period. Further, as an addition to the modern presence/absence 214 data, we also investigated if we could improve the model predictive performance by adding climate data 215 from the georeferenced fossil sites to the training data sets.

216 Different modelling techniques were fitted to the training data sets (see Supporting Information) and 217 their predictions were evaluated on present and past data sets. For present data, the Area Under the 218 Curve (AUC) metric was computed on cross-validated test data sets and on a sample of 1,000 test data 219 points randomly sampled within the European region. Model predictions of the past were evaluated 220 using fossil records as a test data set, and by computing sensitivity.

221 The Ensemble method in BIOMOD, that includes the uncertainty in predictions arising from the 222 choice of model algorithm, was finally selected to predict ptarmigan species probabilities starting from 223 the present and then for every 1,000 year back to $20 \mathrm{cal} \mathrm{kBP}$. Predictions were also made of the future 224 ranges of ptarmigan for the years 2070-2100. For each time period, landscape metrics were calculated 225 for patches of favourable habitats at the $0.5 \times 0.5^{\prime}$ resolution. We estimated the percentage of favourable 226 pixels in the landscape and the degree of fragmentation, given by the number and the average area of 227 suitable habitat patches within the region, using the R library SDMtools (McGarigal et al. 2002; 228 VanDerWal et al. 2012). A pixel was classified as favourable when the probability of presence was 229 above 0.5 . 


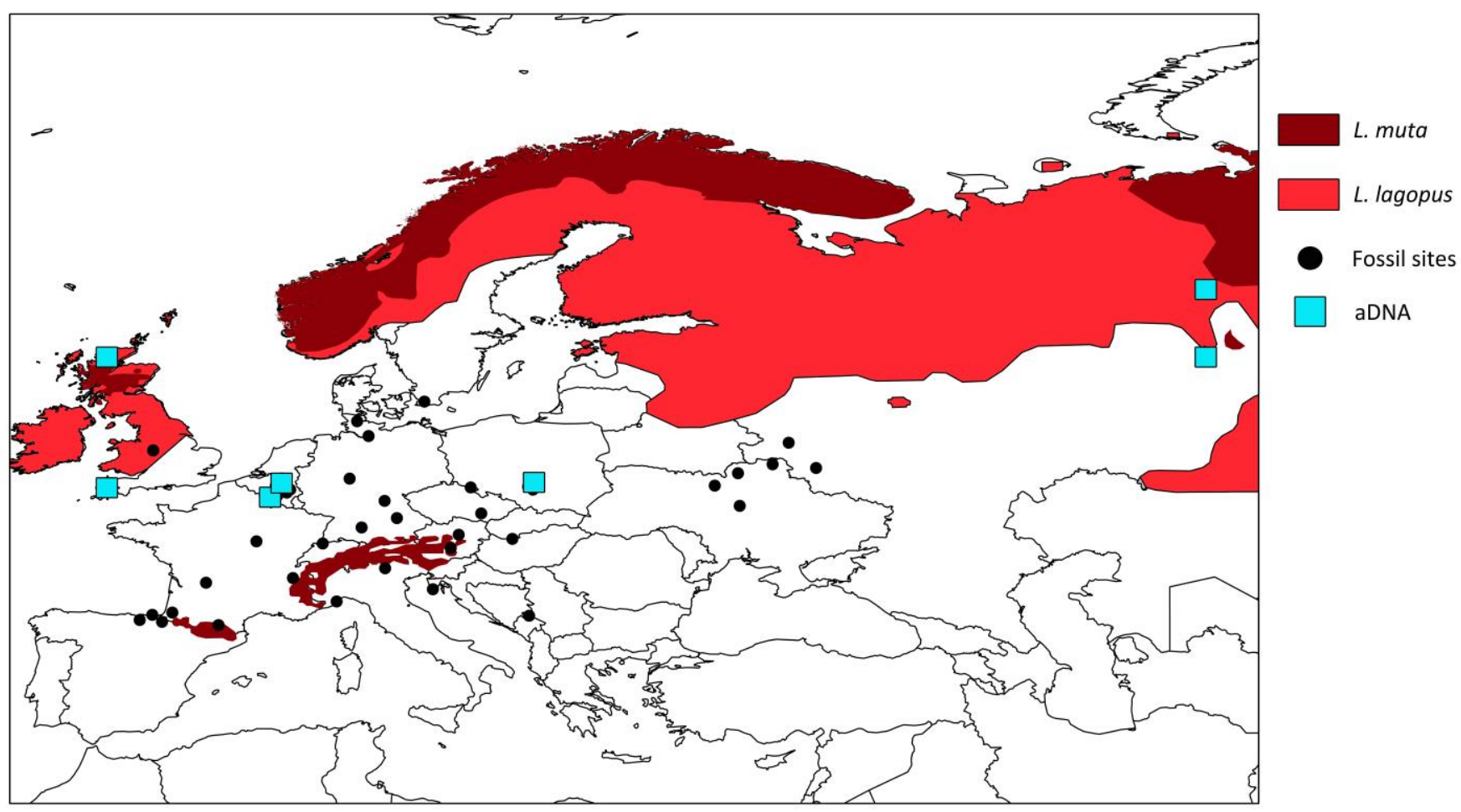

Figure 1 Present European distribution of willow (L. lagopus) and rock (L. muta) ptarmigan, paleontological sites 233 with Lagopus fossil remains (filled circles) used in the species distribution model training (obtained from Tyrberg 234 1998; Tyrberg 2008), and the sites from where successful ancient DNA sequences were retrieved (blue squares). 
Scenario 1

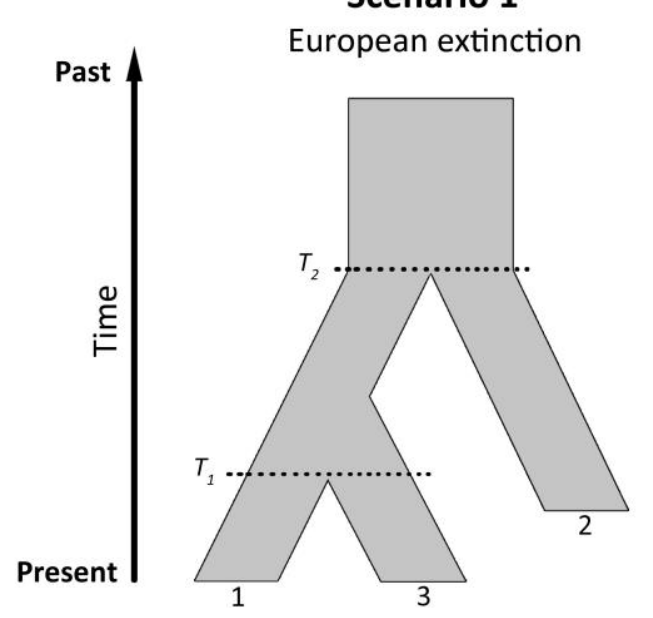

Scenario 2

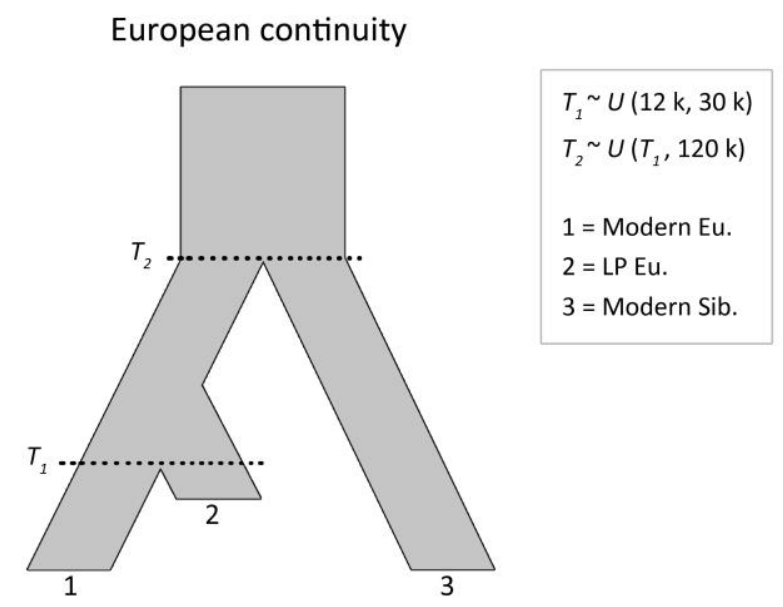

Figure 2 Models and associated priors used in the coalescent simulations of the origin of European ptarmigan 241 populations. Scenario 1 corresponds to an extinction of the Late Pleistocene (LP) European population, followed 242 by a post-glacial colonisation from Siberia. Scenario 2 corresponds to a genetic continuity in Europe over the 243 Pleistocene-Holocene transition, meaning that ptarmigans were able to follow the geographic shifts in suitable 244 habitat that was associated with post-glacial climate warming. The same models are used for both willow and rock 245 ptarmigan. See Tables S2 and S3 for details on the grouping of samples.

\section{RESULTS}

\section{Phylogenetic and Demographic analyses}

252 We successfully retrieved ancient DNA sequences from 42 Late Pleistocene Lagopus spp. bones, 253 originating from 7 European palaeontological sites (Table S1 to S3). Of these, 27 were found to be willow ptarmigan (from 6 sites) and 15 rock ptarmigan (from 5 sites). The modern data set included 36 willow and 64 rock ptarmigan sequences sampled from their complete Holarctic distributions (Table S2 and S3).

257 In both species, two major haplogroups were found in the modern dataset; a western (Europe) and an eastern (Russia/Siberia and North America) (Fig. 3). Furthermore, an intermediate group was found for rock ptarmigan, consisting of birds from Iceland, Svalbard and Greenland. The two major haplogroups 
were also found in the Late Pleistocene dataset, although that only included European samples, and in both ptarmigan species two haplotypes were shared between the modern and the glacial populations (Fig. 3). In the modern European populations, we observed a phylogeographic structure in both willow and rock ptarmigan (Fig. S3, Tables S2 and S3). However, this was not the case for the glacial European population of the respective species, where haplotypes were instead distributed more or less randomly among geographic regions (Fig. S3, Tables S2 and S3).

The analyses of molecular variance showed that, for both species, the structure that maximised the genetic differentiation among groups (i.e. had the highest $F_{C T}$ value) was with modern and ancient European samples together in one group, and modern Siberian samples in a separate (willow ptarmigan $F_{C T}=0.24, p=0.04$; rock ptarmigan $F_{C T}=0.57, p=0.03$ ). The other hierarchical groupings analysed produced $F_{C T}$ values below 0.03 (willow ptarmigan) and 0.22 (rock ptarmigan), and were non271 significant.

272 The Skyline plots constructed in BEAST did not reveal any large temporal changes in effective population size within Western Europe, for either species. However, a comparison between the two species' Skyline plots suggests that willow ptarmigan has always been the more abundant species throughout the investigated time period (Fig. S4).

\section{Approximate Bayesian Computation}

The scenario comparison yielded a strong support for the second historic scenario, in which modern European populations descend from the sampled Late Pleistocene European populations, for rock ptarmigan (Bayes factor, $\mathrm{BF},=5.6-7,506)$, but not for willow ptarmigan $(\mathrm{BF}=0.5-0.9)($ Table S6). The 50 simulation replicates with different acceptance thresholds also produced similar results for rock ptarmigan, all supporting the same scenario, while for willow ptarmigan the best supported scenario shifted among replicates (i.e. with the thresholds used).

A similar result was obtained from the model choice for demographic scenarios (Table S7), where the 285 rock ptarmigan analyses gave a modest but consistent support (except with the logistic regression) for a population growth in Western Europe following the onset of Holocene climate warming ( $\mathrm{BF}=2.0$ 3.3). For willow ptarmigan, none of the analysed scenarios gained a higher support than the alternatives. Replicates including population structure during the Holocene and high mutation rates also confirmed the described pattern (data not shown). The estimation of female effective population size in Western 
290 Europe prior to the Pleistocene-Holocene transition suggested that willow ptarmigan was more common 291 than rock ptarmigan (Fig. S5).

292 We found a very good fit of the chosen scenarios to the actual data, where the observed values of the 293 summary statistics frequently fell in the 95\% highest density intervals (HDI) of their respective 294 predictive distributions (the distributions of the summary statistics after rejection; Figs. S6 to S9).

295 The pseudo-observed datasets (PODs) analyses showed that the statistical power for choosing the right 296 scenario was between 0.65 and 0.85, and increased to 0.88-0.94 when the observed Bayes factor was 297 used as a reference (i.e. only the PODs with values equal to or larger than the observed one were taken 298 into account). The first estimate reflects the probability of choosing the correct scenario without 299 considering the obtained results, whereas the latter could be interpreted as the probability that our 300 scenario choice is correct, given the observed support.

\section{Species Distribution Modelling}

\section{Model calibration and evaluation}

304 Not surprisingly, models performed better in predicting past species distributions when they were 305 trained on fossil records, regardless of sample size (Fig. S10). Also, the predictive performance of the 306 past for models trained on fossil records varied with sample size: performance decreased when 307 increasing sample size. Models trained on the smallest sample size $(n=500)$ were therefore the best 308 whatever the geographical extent of the training data set. In contrast, performance to predict the present was lower for models trained on fossil records, but increased with increasing sample size. However,

310 since models trained on fossils and on small sample size still performed well to predict in present time, 311 we chose this strategy to predict ptarmigan distributions for the whole time period. Finally, models 312 trained on the whole Eurasian distribution did not outperform models trained on Europe, except for the 313 past predictions of rock ptarmigan (L. muta). In the final analyses for both species, we therefore used 314 models trained on the European distribution, including fossil sites, with a sample size of 500. Details on 315 the contribution of each ecological variable to the model, as well as species' response curves along main 316 gradients are provided in the Supporting Information (Figs. S11 and S12).

\section{Past ptarmigan distributions}

318 For each time period, the proportion of suitable habitat in Europe was four times higher for willow 319 ptarmigan than for rock ptarmigan (41\% and $10 \%$ in mean over the last 20 thousand years, 
respectively, see Figs. 3 and 4). However, for willow ptarmigan, the projections showed that the

321 proportion of suitable habitat in the landscape is more restricted today (34\% suitable pixels) than at any 322 time before. The period with most suitable habitat for this species was between 5 and 13 cal kBP 323 (although a decrease in availability was observed at $10 \mathrm{cal} \mathrm{kBP}$ ), and reached the maximum predicted 324 extent at 13 cal kBP with $45 \%$ suitable pixels. For rock ptarmigan, the proportion of suitable habitat 325 was higher today and at $1 \mathrm{cal} \mathrm{kBP}(11 \%$ and $11.5 \%$, respectively) than during the period between 2 to $32617 \mathrm{cal} \mathrm{kBP}$, with a minimum availability at 14 cal $\mathrm{kBP}$ (6\% suitable pixels). Before that, the habitat 327 availability was higher than today, with a maximum predicted extent occurring at 20 cal kBP with $19 \%$ 328 suitable pixels.

329 Regarding the continuity of suitable habitat patches, the predicted range of both ptarmigan species 330 were found to be less fragmented today than during the last 20 thousand years, although similar values 331 as today were estimated for the period 18 to 20 cal kBP (Figs. 3 and 4). The maximum predicted 332 fragmentation occurred at $12 \mathrm{cal} \mathrm{kBP}$ and $13 \mathrm{cal} \mathrm{kBP}$ for willow and rock ptarmigan, respectively, 333 corresponding approximately to the warm Bølling-Allerød interstadial. During the whole time period, 334 rock ptarmigan had a more fragmented available habitat than willow ptarmigan, with a higher number of suitable patches but a smaller mean patch area.

\section{Future ptarmigan distributions}

338 For the time period 2070 to 2100, our models (based on climate emission scenario B1 and A2) projected that the proportion of available habitat for both species will reach the lowest levels observed during the last 20 thousand years (Figs. 3 and 4). For willow ptarmigan, the proportion of suitable pixels was predicted to be reduced by at least $1 / 3$ from today, whereas nearly half of the habitat currently available for rock ptarmigan was predicted to disappear by 2070-2100. Also, future habitats for both species were predicted to be more fragmented than today (Figs. 3 and 4), with the number of available patches becoming as many as estimated for 1 cal $\mathrm{kBP}$ (i.e. more than today) and the mean patch area being as small as the minimum observed during the Late Pleistocene (which occurred approximately between 10 
(a)
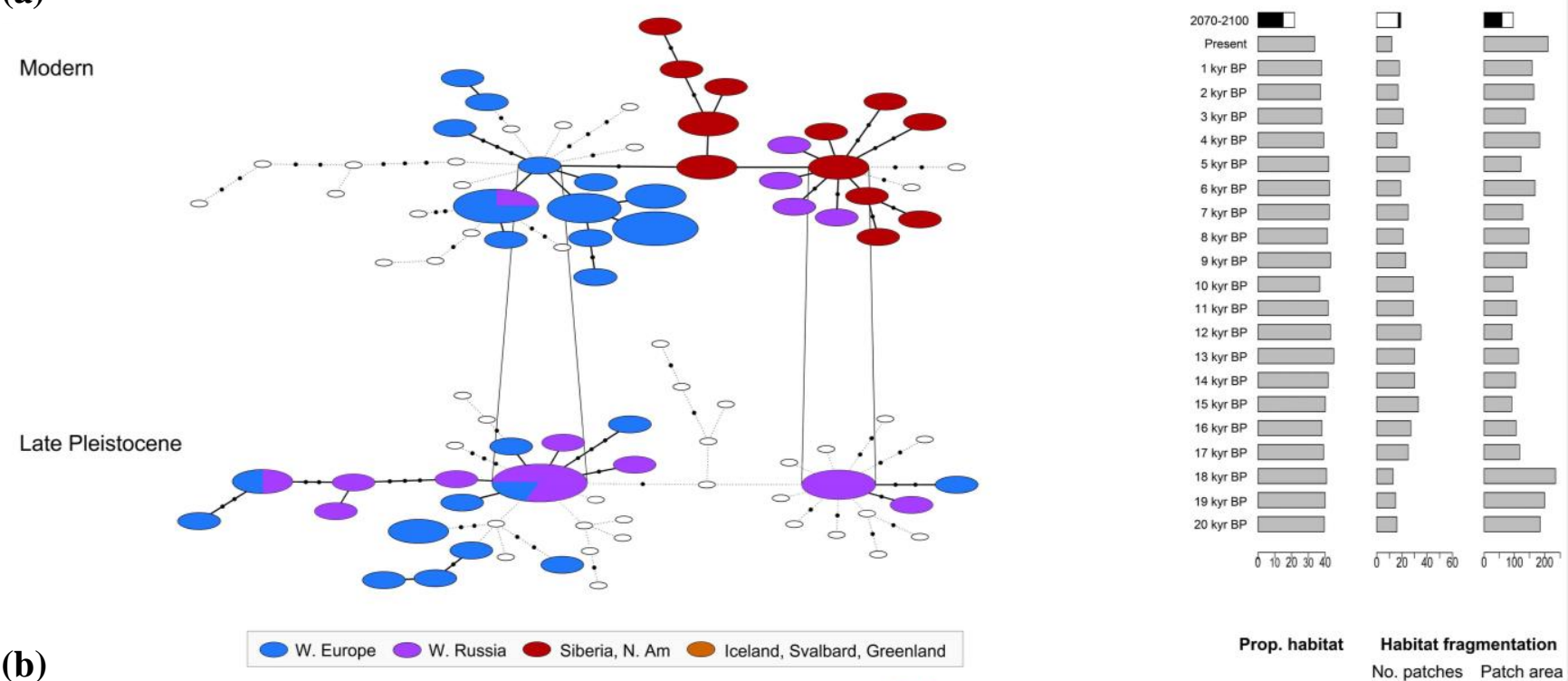

(b)
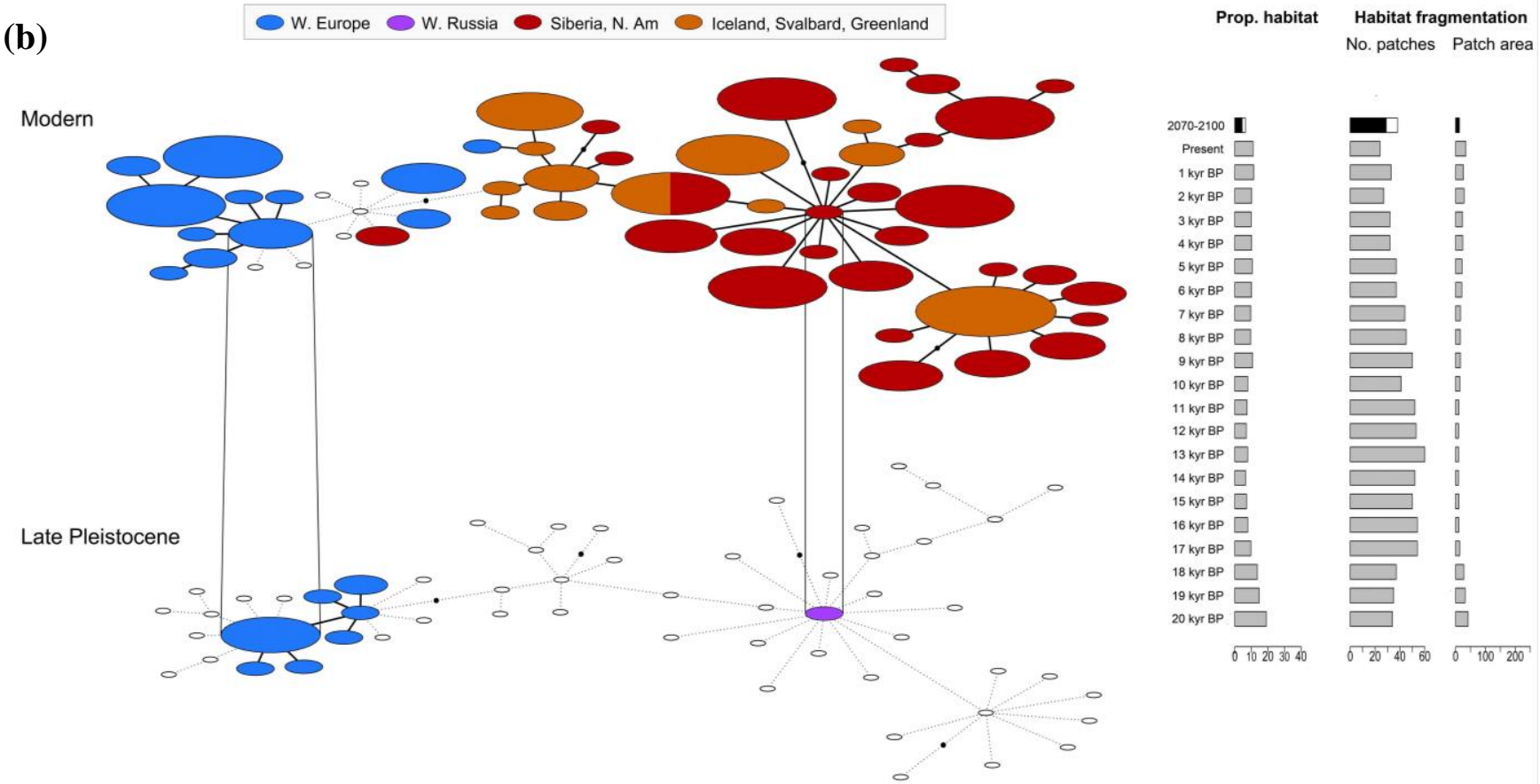

Figure 3 Temporal network of all haplotypes found in modern and Late Pleistocene willow (a) and rock (b) ptarmigan. Vertical lines connect the haplotypes that are shared between both time periods, while empty circles

353 indicate a missing haplotype in one time period that is present in the other. Haplotypes separated by one mutation 354 are connected with a line, while black dots show additional mutations. The number of individuals sharing a 355 haplotype is reflected by its size, with the largest reflecting $\geq 10$ individuals. See Fig. S3 and Tables S2 and S3 for 356 haplotype information. Barplots to the right show temporal changes in the proportion of available habitat and the 357 degree of habitat fragmentation in Europe, illustrated as number of patches and median patch area, as estimated 
358 from the SDM for each species. The future projections, averaged for 2070 to 2100 , are shown for both climate 359 scenario B1 (white bar) and A2 (black bar).

360

361

362

363

364

365 
Back-casted distributions

Willow ptarmigan

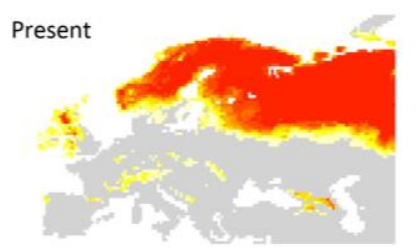

4 cal kBP
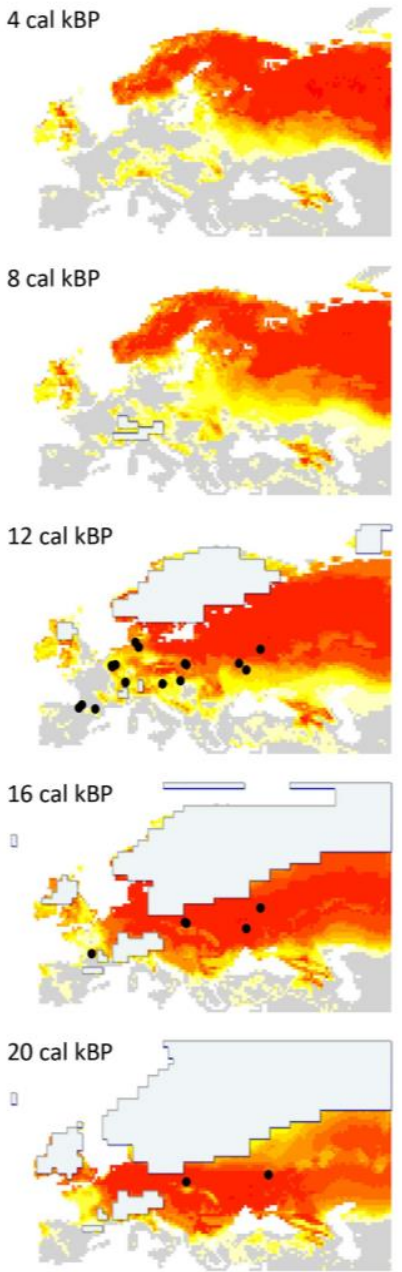

Rock ptarmigan
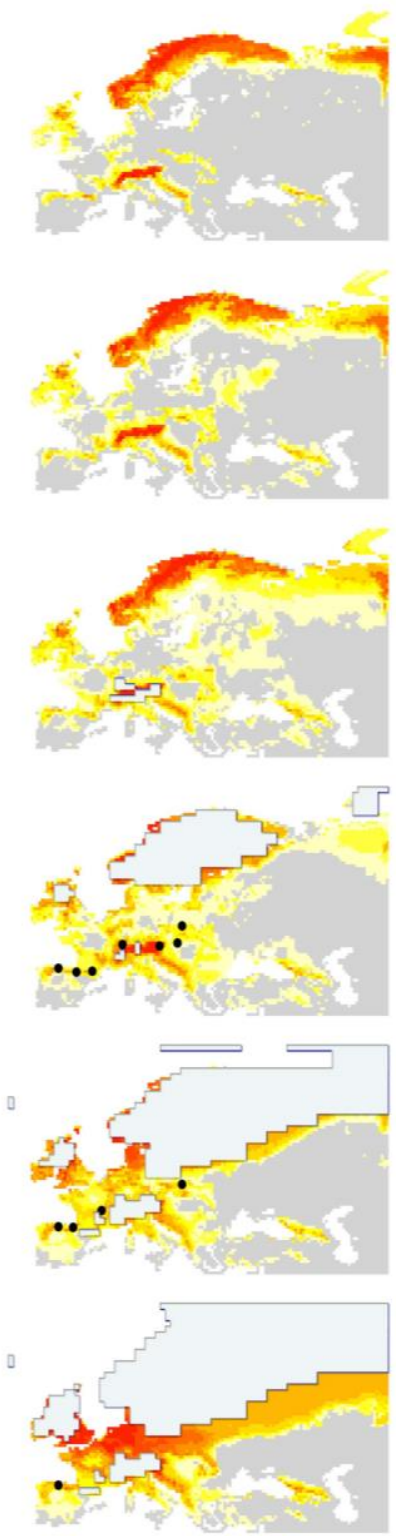

Future distributions

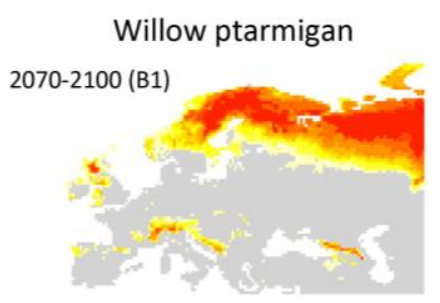

Rock ptarmigan
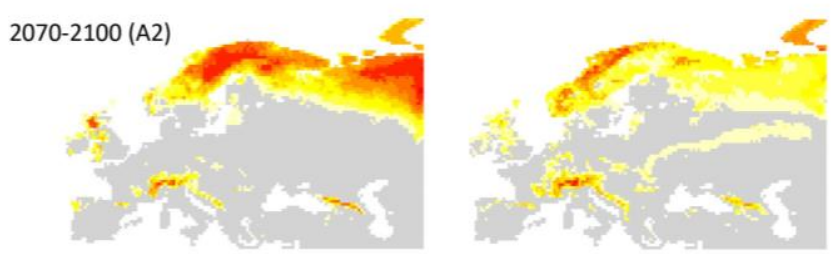

368 Figure 4 Projected occurrence probabilities (from 0 to 1) for willow ptarmigan (left panel) and rock ptarmigan 369 (right panel), at present and back to 20 thousand calendar years before present (cal kBP). Fossil site locations of 370 different ages that have been used in the training and testing data sets are illustrated with filled circles. Also 371 shown to the right are predictions of future distributions, averaged for the period 2070 to 2100 , based on climate 372 scenario B1 and A2. 


\section{DISCUSSION}

The modern Holarctic mitochondrial genetic variation in the two ptarmigan species was divided into two major haplogroups; a western and an eastern, and these were also found in the Late Pleistocene European data sets. If populations managed to track their habitat across the Pleistocene-Holocene transition, we would expect that the modal haplotypes in the modern European populations would also be found in the glacial populations, due to genetic founder effects known to occur during postglacial colonisations of new areas (e.g. Hewitt 1999). Interestingly, this is what we observed for both willow (Lagopus lagopus) and rock (Lagopus muta) ptarmigan, where the modal modern European haplotypes were identical to the most common haplotypes in the two glacial datasets. A genetic continuity in Europe from the Late Pleistocene up until today was also the best scenario in the analyses of molecular variance (AMOVA), where the most probable genetic structure was when glacial and modern European samples were grouped together, while modern Siberian samples made up a separate group. Furthermore, the Bayesian coalescent simulations also gave support to the scenario of long-term genetic continuity in European rock ptarmigan. However, no clear support for either of the different analysed scenarios could be retrieved from the Bayesian coalescent simulations of the willow ptarmigan dataset.

In congruence with the genetic results, the back-casted species distribution models revealed that although environmental conditions in Europe have varied substantially over the last 20 millennia, there have always existed suitable ptarmigan habitats somewhere, which is an important prerequisite for population survival into the present. Based on the two sister species' modern habitat preferences, we could assume that the climate warming at the end of the last Ice Age would have resulted in somewhat different population responses. However, our genetic results show that both seem to have been able to track their shifting habitats to high latitude and altitude regions in Europe, keeping pace with the rapidly changing environment. This continuity is in contrast to the dynamics observed in earlier studies on 398 mammals (e.g. Dalén et al. 2007; Lagerholm et al. 2014; Palkopoulou et al. 2016) and might be explained by the ptarmigans' flight capability, which although they are not strong flyers would have made them less dependent on the connectivity between suitable habitat patches. On the other hand, the previously reported body size reduction of both species (Bochenski 1985; Potapova 1986; Stewart 1999) could suggest that their survival was not just facilitated by successful dispersal, but might also have been coupled with adaptation, or adjustment by phenotypic plasticity (Gienapp et al. 2008). For example, 
ptarmigan might have changed their diet to match the habitat alterations during post-glacial climate 405 warming (Stewart 1999; Stewart 2007).

406 Among the analysed Late Pleistocene Lagopus spp. fossil remains, the majority turned out to be from 407 willow ptarmigan (L. lagopus). The species was also found to have had approximately 4 times more 408 available habitat than glacial rock ptarmigan, as well as a higher genetic variation (Fig. 3 and Table S5) 409 and larger effective population size (Figs. S4 and S5). Our results therefore suggest that willow 410 ptarmigan was the dominant Lagopus species in the tundra-steppes of midlatitude Europe during the 411 cold Late Pleistocene, which is also in line with the demographic inferences made from modern 412 genomes (Kozma et al. 2016). Possibly, rock ptarmigan has a more restricted climatic niche than its 413 sister species, and by being dependent on rocky, high alpine terrain it thus had access to fewer suitable 414 areas during the Late Pleistocene, when the major European mountain ranges were glaciated. Consistent 415 with this, the $\mathrm{ABC}$ results also indicated that Western European rock ptarmigans experienced a 416 population increase after the transition to the warmer Holocene period (Table S7). The niche separation 417 of the two species into lower and high alpine habitats can also be seen today, where willow ptarmigan is 418 absent from the high mountains of the Alps and the Pyrenees although the distribution models suggest 419 the climate in these areas to be favourable (Figs. 1 and 4). The rock ptarmigan's dependency on rocky 420 terrain would also imply that the species had a more fragmented range than willow ptarmigan during the 421 Late Pleistocene. The back-casted species distributions supports this idea, showing that willow 422 ptarmigan had more continuous patches of available habitat than rock ptarmigan (Figs. 3 and 4).

423 Although rock ptarmigan appear to have had a more fragmented distribution in Ice Age Europe than 424 willow ptarmigan, the general lack of phylogeographic structure within the glacial data sets of both 425 species indicates that there were no major barriers to dispersal between different parts of the range. The 426 observed differentiation between modern European populations of willow and rock ptarmigan (Fig. S3) 427 is therefore probably a result of their recent range contractions and isolation in different Holocene 428 interglacial refugia (Hewitt 1996). Consequently, the modern subspecies red grouse (L. lagopus scotica), 429 an endemic to the British Isles previously proposed to have diverged from other willow ptarmigan 430 before the Last Glacial Maximum (Huntley et al. 2013), thus appears to have evolved during the last 11 431 thousand years.

432 Our findings of successful range shifts during past climate changes are encouraging for the future 433 viability of both ptarmigan species, which like many other cold-adapted species are threatened by 
434 predicted habitat decreases due to global warming (e.g. Sala et al. 2000; Smith et al. 2013; Stewart et al. 435 2010). However, an ability to respond to climate changes in the past does not necessarily mean that 436 similar habitat tracking will occur in the future. In many regions, the distributions of these species are 437 already at the limits of possible areas to colonise, and so they are restricted to Arctic regions or southern 438 alpine "sky islands" (Hampe \& Jump 2011). Our forecasts of ptarmigan distributions in the years 20704392100 show that global warming will further reduce the amount of available habitat, and also 440 substantially increase the degree of fragmentation. In parts of the current European distribution, there 441 might only be very small, if any, areas left that fulfil the environmental requirements of willow or rock 442 ptarmigan. Populations in these areas, such as in the isolated British Isles, might therefore need to adapt 443 to a warmer environment in order to survive. Interestingly, the lack of moulting to a white winter 444 plumage observed in the red grouse (L. lagopus scotica) could possibly be such an ongoing adaptation.

\section{ACKNOWLEDGMENTS}

455 We are grateful to the Swedish Museum of Natural History for giving us access to modern museum 456 specimens, and Daniela Kalthoff (Swedish Museum of Natural History), Zlatozar Boev (National 457 Museum of Natural History, Sofia) and Cécile Mourer-Chauviré (Université de Lyon) for providing 458 Pleistocene Lagopus spp. samples. We also thank Luigi Maiorano (Sapienza University of Rome) for 459 contributing with past climatic data sets corrected for anomalies. The genetic analyses were funded 460 through grants from the Centre for Ecology and Evolution (CEE) research fund in the UK, and 461 FORMAS through the FP6 BiodivERsA ERA-NET program. LD and ESC also acknowledges support 462 from the Swedish Research Council and the Strategic Research Programme EkoKlim at Stockholm 463 University, respectively. 


\section{REFERENCES}

464

465Bennett KD, Tzedakis PC, Willis KJ (1991) Quaternary Refugia of North European Trees. Journal of 466 Biogeography, 18, 103-115.

467BirdLife_International (2012a) Lagopus lagopus. In: IUCN 2012. IUCN Red List of Threatened Species. $468 \quad$ Version 2012.2.

469BirdLife_International (2012b) Lagopus muta. In: IUCN 2012. IUCN Red List of Threatened Species. $470 \quad$ Version 2012.2.

471Bochenski Z (1985) Osteological Differentiation in Willow Grouse. Fortschritte der Zoologie, 69-72

472

473Dalén L, Nyström V, Valdiosera C, et al. (2007) Ancient DNA reveals lack of postglacial habitat $474 \quad$ tracking in the arctic fox. Proceedings of the National Academy of Sciences of the United States 475 of America, 104, 6726-6729.

476Darnault R, Rolland Y, Braucher R, et al. (2012) Timing of the last deglaciation revealed by receding 477 glaciers at the Alpine-scale: impact on mountain geomorphology. Quaternary Science Reviews, $478 \quad 31,127-142$.

479Drovetski SV (2003) Plio-Pleistocene climatic oscilations, Holarctic biogeography and speciation in an $480 \quad$ avian subfamily. Journal of Biogeography, 30, 1173-1181.

481Drummond AJ, Rambaut A, Shapiro B, Pybus OG (2005) Bayesian Coalescent Inference of Past $482 \quad$ Population Dynamics from Molecular Sequences. Mol Biol Evol, 22, 1185-1192.

483Drummond AJ, Suchard MA, Xie D, Rambaut A (2012) Bayesian phylogenetics with BEAUti and the $484 \quad$ BEAST 1.7. Molecular Biology and Evolution.

485Engler R, Randin CF, Vittoz P, et al. (2009) Predicting future distributions of mountain plants under 486 climate change: does dispersal capacity matter? Ecography, 32, 34-45.

487Espíndola A, Pellissier L, Maiorano L, et al. (2012) Predicting present and future intra-specific genetic $488 \quad$ structure through niche hindcasting across 24 millennia. Ecology Letters, 15, 649-657.

489Excoffier L, Lischer HEL (2010) Arlequin suite ver 3.5: a new series of programs to perform population 490 genetics analyses under Linux and Windows. Molecular Ecology Resources, 10, 564-567.

491Fagundes NJR, Ray N, Beaumont M, et al. (2007) Statistical evaluation of alternative models of human 492 evolution. Proceedings of the National Academy of Sciences, 104, 17614-17619.

493Gienapp P, Teplitsky C, Alho JS, Mills JA, Meril̈̈ J (2008) Climate change and evolution: 494 disentangling environmental and genetic responses. Molecular Ecology, 17, 167-178.

495Hall TA (1999) BioEdit: a user-friendly biological sequence alignment editor and analysis program for $496 \quad$ Windows 95/98/NT. Nucleic Acids Symposium Series, 41, 95-98.

497Hampe A, Jump AS (2011) Climate Relicts: Past, Present, Future. Annual Review of Ecology, Evolution, $498 \quad$ and Systematics, 42, 313-333.

499Hansen BB, Grøtan V, Aanes R, et al. (2013) Climate Events Synchronize the Dynamics of a Resident $500 \quad$ Vertebrate Community in the High Arctic. Science, 339, 313-315.

501Hewitt GM (1996) Some genetic consequences of ice ages, and their role in divergence and speciation. 502 Biological Journal of the Linnean Society 58, 247-276.

503Hewitt GM (1999) Post-glacial re-colonization of European biota. Biological Journal of the Linnean $504 \quad$ Society, 68, 87-112.

505Ho SYW, Lanfear R, Bromham L, et al. (2011) Time-dependent rates of molecular evolution. Molecular $506 \quad$ Ecology, 20, 3087-3101. 
507Hodgson JA, Thomas CD, Dytham C, Travis JMJ, Cornell SJ (2012) The Speed of Range Shifts in $508 \quad$ Fragmented Landscapes. PLoS ONE, 7.

509Huntley B, Allen JRM, Barnard P, Collingham YC, Holliday PR (2013) Species distribution models 510 indicate contrasting late-Quaternary histories for Southern and Northern Hemisphere bird $511 \quad$ species. Global Ecology and Biogeography, 22, 277-288.

512Höglund J, Wang B, Axelsson T, Quintela M (2013) Phylogeography of willow grouse (Lagopus 513 lagopus) in the Arctic: taxonomic discordance as inferred from molecular data. Biological $514 \quad$ Journal of the Linnean Society, 110, 77-90.

515IPCC (2001) Working Group 1: The Scientific Basis. In: Climate Change 2001 eds. Houghton JT, Ding $516 \quad$ Y, Griggs DJ, et al.).

517Kerr JT, Pindar A, Galpern P, et al. (2015) Climate change impacts on bumblebees converge across $518 \quad$ continents. Science, 349, 177-180.

519Kozma R, Melsted P, Magnússon KP, Höglund J (2016) Looking into the past - the reaction of three 520 grouse species to climate change over the last million years using whole genome sequences. $521 \quad$ Molecular Ecology, 25, 570-580.

522Lagerholm VK, Sandoval-Castellanos E, Ehrich D, et al. (2014) On the origin of the Norwegian 523 lemming. Molecular Ecology, 23, 2060-2071.

524Maiorano L, Cheddadi R, Zimmermann NE, et al. (2013) Building the niche through time: using 13,000 525 years of data to predict the effects of climate change on three tree species in Europe. Global $526 \quad$ Ecology and Biogeography, 22, 302-317.

527McGarigal K, Cushman SA, Neel MC, Ene E (2002) FRAGSTATS: Spatial Pattern Analysis Program 528 for Categorical Maps, University of Massachusetts, Amherst.

529Mitchell TD, Carter TR, Jones PD, Hulme M, New M (2004) A comprehensive set of high-resolution 530 grids of monthly climate for Europe and the globe: the observed record (1901-2000) and 16 531 scenarios (2001-2100). Tyndall Centre Working Paper No. 55, July 2004; available at $532 \quad$ http://www.tyndall.ac.uk/sites/default/files/wp55.pdf.

533Nylander JAA (2004) MrModeltest v2, p.

534, http://www.abc.se/ nylander/mrmodeltest $2 /$ mrmodeltest2.html.

535Nyström J, Ekenstedt J, Engström J, Angerbjörn A (2005) Gyr Falcons, ptarmigan and microtine rodents 536 in northern Sweden. Ibis, 147, 587-597.

537Palkopoulou E, Baca M, Abramson NI, et al. (2016) Synchronous genetic turnovers across Western $538 \quad$ Eurasia in Late Pleistocene collared lemmings. Global Change Biology, 22, 1710-1721.

539Palkopoulou E, Dalén L, Lister AM, et al. (2013) Holarctic genetic structure and range dynamics in the $540 \quad$ woolly mammoth. Proc Biol Sci, 280, 7.

541Pedersen HC, Steen H, Kastdalen L, et al. (2004) Weak compensation of harvest despite strong density542 dependent growth in willow ptarmigan. Proceedings of the Royal Society of London. Series B: 543 Biological Sciences, 271, 381-385.

544Pithan F, Mauritsen T (2014) Arctic amplification dominated by temperature feedbacks in contemporary $545 \quad$ climate models. Nature Geosci, 7, 181-184.

546Potapov R, Potapov E (2011) Willow and Rock Ptarmigan monitoring in Russia: An historic overview. 547 In: Gyrfalcons and Ptarmigan in a Changing World eds. Watson RT, Cade TJ, Fuller M, Hunt $548 \quad$ G, Potapov E). The Peregrine Fund, Boise, Idaho, USA.

549Potapova O (1986) Grouse of the genus Lagopus in the Pleistocene of the Northern Urals. Proceed. $550 \quad$ Zool. Institute, USSR Academy of Sciences, 147, 46-58. 
551Prost S, Anderson CNK (2011) TempNet: a method to display statistical parsimony networks for 552 heterochronous DNA sequence data. Methods in Ecology and Evolution, 2, 663-667.

553Rambaut A, Drummond AJ (2007) Tracer v1.4: MCMC trace analyses tool, $554 \quad$ http://tree.bio.ed.ac.uk/software/tracer/.

555Sala OE, Stuart Chapin F, III, et al. (2000) Global Biodiversity Scenarios for the Year 2100. Science, $556 \quad 287,1770-1774$.

557Sandoval-Castellanos E, Palkopoulou E, Dalén L (2014) Back to BaySICS: A User-Friendly Program 558 for Bayesian Statistical Inference from Coalescent Simulations. PLoS ONE, 9, e98011.

559Serreze MC, Barry RG (2011) Processes and impacts of Arctic amplification: A research synthesis. $560 \quad$ Global and Planetary Change, 77, 85-96.

561Smith SE, Gregory RD, Anderson BJ, Thomas CD (2013) The past, present and potential future 562 distributions of cold-adapted bird species. Diversity and Distributions, 19, 352-362.

563Stewart JR (1999) Intraspecific Variation in Modern and Quaternary European Lagopus. In: Avian 564 Paleontology at the Close of the 20th Century. Proc. of the 4th International Meeting of the 565 Society of Avian Paleontology and Evolution (ed. Olson SL). Smithsonian Contributions to 566 Paleobiology 89: 159-168, Washington, D.C.

567Stewart JR (2007) An Evolutionary Study of Some Archaeologically Significant Avian Taxa in the 568 Quaternary of the Western Palaearctic Hadrian Books Ltd, Oxford.

569Stewart JR, Lister AM, Barnes I, Dalén L (2010) Refugia revisited: individualistic responses of species $570 \quad$ in space and time. Proceedings of the Royal Society B: Biological Sciences, 277, 661-671.

571Team RC (2014) R: A language and environment for statistical computing. R Foundation for Statistical 572 Computing, Vienna, Austria. http://www.R-project.org/.

573Thomas CD, Cameron A, Green RE, et al. (2004) Extinction risk from climate change. Nature, 427, $574 \quad 145-148$.

575Thuiller W, Lafourcade B, Engler R, Araújo MB (2009) BIOMOD - a platform for ensemble 576 forecasting of species distributions. Ecography, 32, 369-373.

577Tyrberg T (1998) Pleistocene birds of the Palearctic: a catalogue Nuttall Ornithological Club $578 \quad$ Cambridge.

579Tyrberg T (2008) Pleistocene birds of the Palearctic. http://web.telia.com/ u11502098/pleistocene.pdf. 580Urban MC (2015) Accelerating extinction risk from climate change. Science, 348, 571-573.

581VanDerWal J, Falconi L, Januchowski S, Shoo L, Storlie C (2012) Species Distribution Modelling 582 Tools: Tools for processing data associated with species distribution modelling exercises, $583 \quad$ http://www.rforge.net/SDMTools/.

584 